Radiotherapy utilization

\title{
Radiotherapy utilization in developing countries: An IAEA study
}

\author{
Eduardo Rosenblatt a,*, Elena Fidarova ${ }^{a}$, Eduardo H. Zubizarreta ${ }^{\mathrm{a}}$, Michael B. Barton ${ }^{\mathrm{b}}$, \\ Glenn W. Jones ${ }^{\mathrm{c}}$, William J. Mackillop ${ }^{\mathrm{d}}$, Lisbeth Cordero ${ }^{\mathrm{e}}$, Joel Yarney ${ }^{\mathrm{f}}$, Gerard Lim $^{\mathrm{g}}$, John V. Gan ${ }^{\mathrm{h}}$, \\ Valentin Cernea ${ }^{\mathrm{i}}$, Suzana Stojanovic-Rundic ${ }^{\mathrm{j}}$, Primoz Strojan ${ }^{\mathrm{k}}$, Lotfi Kochbati ${ }^{1}$, Aldo Quarneti ${ }^{\mathrm{m}}$
}

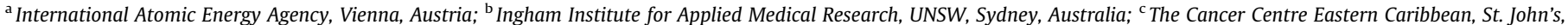

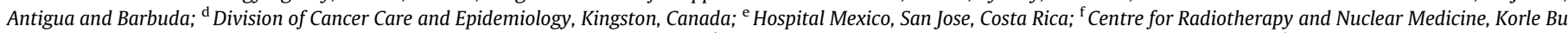

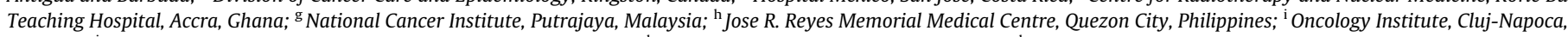

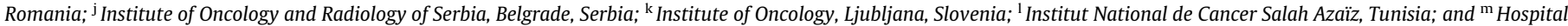
Pereira Rossell, Montevideo, Uruguay
\end{abstract}

\section{A R T I C L E I N F O}

\section{Article history:}

Received 18 February 2018

Received in revised form 9 May 2018

Accepted 15 May 2018

Available online 30 May 2018

\section{Keywords:}

Radiotherapy

Radiation oncology

Utilization rates

Developing countries

\begin{abstract}
A B S T R A C T
Background: The planning of national radiotherapy (RT) services requires a thorough knowledge of the country's cancer epidemiology profile, the radiotherapy utilization (RTU) rates and a future projection of these data. Previous studies have established RTU rates in high-income countries.

Methods: Optimal RTU (oRTU) rates were determined for nine middle-income countries, following the epidemiological evidence-based method. The actual RTU (aRTU) rates were calculated dividing the total number of new notifiable cancer patients treated with radiotherapy in 2012 by the total number of cancer patients diagnosed in the same year in each country. An analysis of the characteristics of patients and treatments in a series of 300 consecutive radiotherapy patients shed light on the particular patient and treatments profile in the participating countries.

Results: The median oRTU rate for the group of nine countries was 52\% (47-56\%). The median aRTU rate for the nine countries was $28 \%$ (9-46\%). These results show that the real proportion of cancer patients receiving RT is lower than the optimal RTU with a rate difference between $10-42.7 \%$. The median percent-unmet need was $47 \%$ (18-82.3\%).

Conclusions: The optimal RTU rate in middle-income countries did not differ significantly from that previously found in high-income countries. The actual RTU rates were consistently lower than the optimal, in particular in countries with limited resources and a large population.
\end{abstract}

Crown Copyright @ 2018 Published by Elsevier B.V. All rights reserved. Radiotherapy and Oncology 128

(2018) 400-405
In developed countries, approximately half of cancer patients have an indication for radiotherapy [1]. Countries that experience the need for radiotherapy infrastructure expansion - often painfully expressed in waiting lists - usually embark on a national strategy for a planned development of their radiotherapy capacity. In this scenario, knowing the radiotherapy utilization (RTU) rates in a country is necessary to inform planning models for future radiotherapy services. This planning requires a thorough knowledge of the national cancer epidemiology profile and a realistic future projection of these data [2,3].

The oRTU rate is the proportion of all cancers with an indication for radiotherapy. In the "Collaboration for Cancer Outcomes Research and Evaluation” (CCORE) model [1] used here, an

\footnotetext{
* Corresponding author at: International Atomic Energy Agency, Wagramer Strasse 5 - A-1400, Vienna, Austria.

E-mail address: rosenblatt21@gmail.com (E. Rosenblatt).

URL: http://www.iaea.org/ (E. Rosenblatt).
}

indication for radiotherapy was defined as a clinical scenario for which radiotherapy is recommended as the treatment of choice because there is evidence that it has a superior clinical outcome compared to alternative treatment modalities including no treatment. The superiority of radiotherapy over other treatment options could be due to better survival, local control, and quality of life or toxicity profiles. In clinical situations where radiation therapy had an equal outcome to other treatment options such as surgery or chemotherapy, all the treatment options were included in the model, and a sensitivity analysis was conducted to determine the range of proportion of patients for whom radiotherapy may be indicated. An evidence-based computation model was used based on data from high-income countries.

Estimates of RTU in developed countries based on expert opinion have found that the desirable RTU rate was in the order of $50 \%$ [4-6]. Patients in low-middle-income countries (LMICs) usually present with more advanced disease. This fact coupled with 
limited access to oncology surgery, result in higher demand for radiotherapy compared with high-income countries (HICs).

In this first study looking at RTU rates in nine middle-income countries following an evidence-based method, the aim was to estimate the actual RTU and compare it with the optimal, to determine the gaps in service provision in these countries.

The objectives of the study were to: (1) estimate the optimal radiotherapy utilization (oRTU) rate; (2) measure the actual rate of radiotherapy utilization (aRTU) in the same countries and (3) assess the characteristics of patient populations, disease profiles, and treatments administered in the participating countries.

\section{Methods}

Countries were selected for this study according to the following criteria: (1) middle-income nations as per the World Bank classification of economies based on a Gross National Income (GNI) per capita (Atlas method) of U\$S 1.026 - 12.475 in the fiscal year 2012 [7], when the study was initiated. (2) Countries located in the four IAEA regions; Africa, Asia, Europe and Latin America. (3) Countries with existing and operational radiotherapy centre(s), (4) with an operational cancer registry, and (5) where a reliable and motivated coordinator could be identified. The countries selected for the study were Costa Rica, Ghana, Malaysia, Philippines, Romania, Serbia, Slovenia, Tunisia, and Uruguay. Table 1 shows the level of robustness, availability and methods for cancer incidence data as per the Globocan-2012 classification. The table also shows the level of economic development (GNI-per capita) and the existence of an operational cancer control plan.

In the CCORE methodological approach, indications for radiotherapy for each cancer site were derived from evidence-based published treatment guidelines issued by reputed national and international organizations. An optimal radiotherapy utilization tree was developed for each cancer site by combining clinical scenarios and epidemiological data using TreeAge Pro $^{\mathrm{TM}}$ software. Patients requiring radiotherapy were counted only once even if they subsequently developed repeated indications for radiotherapy.

The distribution of tumour types for each country was taken from estimations of the International Agency for Research on Cancer (IARC) in their database Globocan-2012 [8]. This database lists 27 cancer types and the total. The list does not include sarcomas (except Kaposi's sarcoma), cancers of unknown primary (CUP) site or "other" categories.

The aRTU rate was calculated as the ratio of the number of new notifiable patients (no retreatments) treated with radiotherapy in 2012 in each country, to the total number of cancer patients diagnosed in the same year. Country coordinators reported separately the total number of new and carryover patients receiving radiotherapy in the index year 2012. They gathered the data from all operational RT centres in their respective countries.

The radiotherapy case-mix profile for each country was determined by prospectively registering 300 consecutive patients receiving radiotherapy at a leading RT centre in each country, capturing detailed data on patient, disease and treatment characteristics from this sample. Country coordinators conducted this prospective data collection filling an 18-item questionnaire for each one of 300 consecutive patients receiving radiotherapy in their respective centres (Appendix I). This form was completed for each patient on treatment and forwarded to the IAEA Data Management Centre. The year 2012 was selected as the index year for calculations to allow correlation of the case-mix and radiotherapy data with estimates of cancer incidence from the Globocan2012 database.

Table 1

Economic development, cancer incidence data and cancer control plans in the 9 target countries.

\begin{tabular}{|c|c|c|c|c|c|c|c|}
\hline 1. & 2. & 3. & 4. & 5. & 6. & 7. & 8. \\
\hline Country & $\begin{array}{l}\text { GNI per } \\
\text { capita } \\
2018 \\
\text { (US\$) }\end{array}$ & Availability and methods of cancer incidence data & $\begin{array}{l}\text { National cancer } \\
\text { control } \\
\text { strategy/plan }\end{array}$ & $\begin{array}{l}\text { National } \\
\text { cancer } \\
\text { registry }\end{array}$ & Scope & Coverage & $\begin{array}{l}\text { Last } \\
\text { year of } \\
\text { data }\end{array}$ \\
\hline Costa Rica & 11824 & $\begin{array}{l}\text { High quality national data or high quality regional (coverage greater } \\
\text { than 50\%) } \\
\text { Rates projected to } 2012\end{array}$ & Yes & Yes & $\begin{array}{l}\text { Population- } \\
\text { based }\end{array}$ & National & 2010 \\
\hline Ghana & 1513 & $\begin{array}{l}\text { Frequency data. Age/sex specific rates for "all cancers" were partitioned } \\
\text { using data on relative frequency of different cancers } \\
\text { (by age and sex) }\end{array}$ & Yes & Yes & $\begin{array}{l}\text { Hospital- } \\
\text { based }\end{array}$ & Subnational & 2012 \\
\hline Malaysia & 9508 & $\begin{array}{l}\text { High quality regional (coverage lower than } 10 \% \text { ) } \\
\text { Estimated as the weighted average of the local rates }\end{array}$ & Yes & Yes & $\begin{array}{l}\text { Population- } \\
\text { based }\end{array}$ & Subnational & 2011 \\
\hline Philippines & 2951 & $\begin{array}{l}\text { High quality regional (coverage between } 10 \% \text { and } 50 \% \text { ) } \\
\text { Estimated as the weighted average of the local rates }\end{array}$ & Yes & Yes & $\begin{array}{l}\text { Population- } \\
\text { based }\end{array}$ & Subnational & 2003 \\
\hline Romania & 9522 & $\begin{array}{l}\text { Regional data (rates) } \\
\text { Estimated from national mortality estimates by modelling, using } \\
\text { incidence mortality ratios derived from recorded data in local cancer } \\
\text { registries in neighbouring countries }\end{array}$ & Yes & Yes & $\begin{array}{l}\text { Population- } \\
\text { based }\end{array}$ & Subnational & 2010 \\
\hline Serbia & 5426 & $\begin{array}{l}\text { High quality regional (coverage between } 10 \% \text { and } 50 \% \text { ) } \\
\text { Estimated from national mortality estimates by modelling, using } \\
\text { incidence mortality ratios derived from recorded data in local cancer } \\
\text { registries in neighbouring countries }\end{array}$ & No & Yes & $\begin{array}{l}\text { Population- } \\
\text { based }\end{array}$ & Subnational & 2010 \\
\hline Slovenia & 21650 & $\begin{array}{l}\text { High quality national data or high quality regional (coverage greater } \\
\text { than } 50 \% \text { ) } \\
\text { Rates projected to } 2012\end{array}$ & Yes & Yes & $\begin{array}{l}\text { Population- } \\
\text { based }\end{array}$ & National & 2010 \\
\hline Tunisia & 3688 & $\begin{array}{l}\text { High quality regional (coverage lower than } 10 \% \text { ) } \\
\text { Estimated as the weighted average of the local rates }\end{array}$ & No & Yes & $\begin{array}{l}\text { Population- } \\
\text { based }\end{array}$ & Subnational & 2004 \\
\hline Uruguay & 15220 & $\begin{array}{l}\text { High quality national data or high quality regional (coverage greater } \\
\text { than 50\%) } \\
\text { Most recent rates applied to } 2012 \text { population }\end{array}$ & Yes & Yes & $\begin{array}{l}\text { Population- } \\
\text { based }\end{array}$ & National & 2008 \\
\hline
\end{tabular}

Sources:

Column 2: GNI per capita: World Bank https://data.worldbank.org/indicator/NY.GNP.PCAP.PP.CD? view=chart.

Column 3: IARC/WHO Globocan-2012, Estimated cancer incidence, mortality and prevalence in 2012.

Columns 4-8: WHO Cancer Country Profiles 2014 - http://www.who.int/cancer/country-profiles/en/\#P. 
We calculated the "percent unmet need" as follows:

Percent unmet need $=[($ optimal $R T U$ rate - actual $R T U$ rate $) /$ optimal $R T U$ rate $]$ $\times 100$

\section{Results}

\section{Optimal RTU rate (oRTU)}

The calculated oRTU rates based on countries incidence data as per Globocan-2012 have been previously reported [9] (Table 2). They were: Costa Rica 47\%, Ghana 51\%, Malaysia 53\%, Philippines $53 \%$, Romania 52\%, Serbia 52\%, Slovenia $48 \%$, Tunisia 56\% and Uruguay $52 \%$. The median oRTU for the nine countries was $52 \%$ ranging from $47 \%$ in Costa Rica to $56 \%$ in Tunisia with a $9 \%$ difference between these two.

\section{Actual RTU rate (aRTU)}

Table 2 displays the optimal (column 10) and actual (column 11) RTU rates for comparison, the gap between them per country (column 12) and the calculated percent unmet need (column 13).

The median aRTU for these nine countries was $28 \%$, compared to a median oRTU of $52 \%$. The lowest aRTU rate was found in Ghana (8.7\%), while the highest was found in Tunisia (46.5\%).

Since the CCORE model, as well as Globocan-2012, excludes non-melanoma skin cancer, this disease entity was not included in the calculation of the actual RTU rates. However, in Table 3, which reflects the characteristics of actual practice in these countries - the calculations include patients with non-melanoma skin cancer. In the two African countries (Tunisia and Ghana), this disease represents the 3rd and 8th most commonly irradiated cancers respectively.

Table 2 shows the total number of patients treated with radiotherapy in each nation (column 7) as well as the total number of new patients, as reported by country coordinators. The difference between these two values includes a small number of patients treated, which are the carryover from the previous year as well as re-irradiated patients.

\section{Patients and treatments characteristics}

Prospective registration of 18 variables in a series of 300 consecutive patients receiving radiotherapy in each participating centre (Uruguay reported on 150 patients) allowed having an overview of the case-mix and stages treated in each country as well as the radiotherapy techniques used (Tables 2 and 3 ).

The mean age of patients treated in these nine centres was 55 years (median 56.7) and the ratio male to females 0.3.

"Centre's delay" was defined as the time in days from the date of registration in the radiotherapy centre to the day of first radiotherapy session. It was a mean of 73 days (median: 28), from 14 days to 215 days.

The ratio curative versus palliative intention treatments was 0.6 meaning that $2 / 3$ of patients were managed with curative intent.

Most patients (87\%) were new patients while the median retreatment rate for the nine countries was $11 \%$ with a range between $7 \%$ (Ghana) and 24\% (Slovenia).

In four countries (Costa Rica, Ghana, Serbia, and Tunisia), sarcomas were among the ten most common cancers receiving radiotherapy. However, Globocan-2012 does not list sarcomas (except Kaposi's sarcoma) among the 27 types of cancer reported.

Fifty-four percent of irradiated patients had had some invasive procedure (including biopsy) before RT. Twenty-one percent of patients were being treated with concomitant chemoradiotherapy.

Of a total of 2548 patients evaluable for treatment technique complexity, $49 \%$ were treated with 2D techniques, $42.6 \%$ with 3D-CRT, $3.2 \%$ with IMRT or equivalent and $5 \%$ with other methods. This represents a total of $46 \%$ of patients treated with conformal radiotherapy techniques including IMRT in these countries.

Thirty-four percent of all patients were treated with hypofractionation, defined as any radiotherapy regimen using daily fractions larger than $2.0 \mathrm{~Gy}$.

Of a total of 2646 anatomic sites treated (Table 4) the distribution was as follows: CNS $11.4 \%$, head-and-neck $12.3 \%$, thoracic tumours $6.5 \%$, abdominal $3.1 \%$, pelvic $26.1 \%$, breast $25.8 \%$, and others including tumours of the limbs (13.5\%). In Table 4 , the sum of all sites irradiated for each country is higher than 300 due to some patients receiving treatment to more than one anatomic site.

\section{Discussion}

The proportion of patients who need RT and who actually receive it, best measures accessibility of radiotherapy in a country. Radiotherapy is prescribed to approximately $47 \%$ of new cancer patients in middle-income countries, while in $55.2 \%$ of patients the prescription is for combined modality therapy [10].

Table 2

Characteristics, radiotherapy infrastructure and RTU rates results in 9 middle-income countries.

\begin{tabular}{|c|c|c|c|c|c|c|c|c|c|c|c|c|}
\hline 1. & 2. & 3. & 4. & 5. & 6. & 7. & 8. & 9. & 10. & 11. & 12. & 13. \\
\hline Country & $\begin{array}{l}\text { Population } \\
\text { (millions) }\end{array}$ & $\begin{array}{l}\text { New } \\
\text { cancer } \\
\text { cases } \\
2012\end{array}$ & $\begin{array}{l}\text { No. } \\
\text { RT } \\
\text { centres }\end{array}$ & $\begin{array}{l}\text { No. tele- } \\
\text { therapy } \\
\text { machines } \\
(2012)\end{array}$ & $\begin{array}{l}\text { Teletherapy } \\
\text { machines } / 1000 \\
\text { cancer cases } \\
(2012)\end{array}$ & $\begin{array}{l}\text { All RT } \\
\text { patients } \\
\text { in } 2012\end{array}$ & $\begin{array}{l}\text { New RT } \\
\text { patients in } \\
2012\end{array}$ & $\begin{array}{l}\text { Re- } \\
\text { irradiation } \\
\text { rate } \\
(\%)\end{array}$ & $\begin{array}{l}\text { Optimal } \\
\text { RTU rate } \\
(\%)\end{array}$ & $\begin{array}{l}\text { Actual } \\
\text { RTU } \\
\text { rate } \\
(\%)\end{array}$ & $\begin{array}{l}\text { Diff. } \\
(10 . \\
\text { minus } \\
11 .) \\
(\%)\end{array}$ & $\begin{array}{l}\text { Unmet } \\
\text { need } \\
(\%)\end{array}$ \\
\hline Costa Rica & 4.793 & 8900 & 4 & 8 & 0.89 & 3487 & 3138 & 10 & 47 & 35 & 12 & 25.5 \\
\hline Ghana & 25.545 & 15800 & 3 & 3 & 0.19 & 1480 & 1376 & 7 & 51 & 9 & 42 & 82.3 \\
\hline Malaysia & 29.321 & 37400 & 21 & 42 & 1.1 & 11636 & 10385 & 12 & 53 & 28 & 25 & 47 \\
\hline Philippines & 96.471 & 98200 & 27 & 34 & 0.34 & 10894 & 10087 & 7.4 & 53 & 10.3 & 42.7 & 80.5 \\
\hline Romania & 21.387 & 78800 & 16 & 23 & 0.29 & 19490 & 17346 & 11 & 52 & 22 & 30 & 57.6 \\
\hline Serbia & 9.846 & 42200 & 6 & 15 & 0.35 & 12739 & 10046 & 21 & 52 & 23.8 & 28 & 54 \\
\hline Slovenia & 2.040 & 11500 & 1 & 8 & 0.7 & 4752 & 3602 & 24 & 48 & 31 & 17 & 35.4 \\
\hline Tunisia & 10.704 & 12200 & 10 & 16 & 1.3 & 6300 & 5670 & 10 & 56 & 46 & 10 & 18 \\
\hline Uruguay & 3.391 & 13357 & 8 & 14 & 1.05 & 5750 & 5020 & 13 & 52 & 37 & 15 & 29 \\
\hline Median & & & & & & & & 11 & 52 & 28 & 24 & 47 \\
\hline
\end{tabular}

Column 2 - UN Population Information Network.

Column 3 - Globocan-2012.

Column 13 - Percent unmet need $=[($ optimal RTU rate - actual RTU rate $) /$ optimal RTU rate $] \times 100$. 


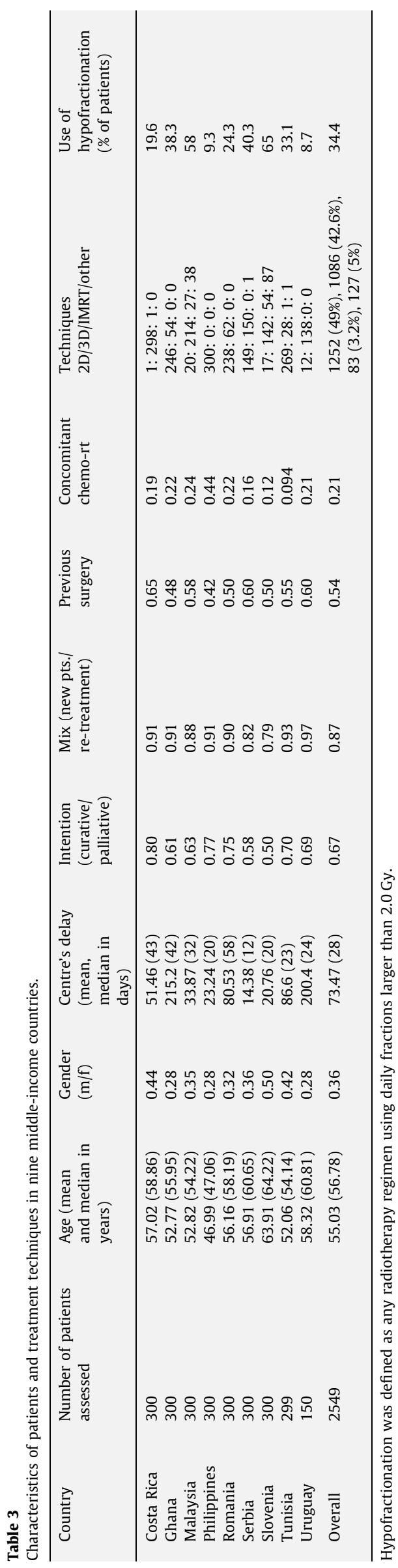

The oRTU rates represent an ideal scenario where all patients who need RT have access to it. In reality, aRTU rates do not reach $100 \%$ of those with an indication for it, even in developed countries, since current calculation models do not include patients' preference or medical contraindications.

Estimates of the need for radiotherapy have been reported using expert opinion including the Delphi panel method [4-6], epidemiological evidence-based assessment (EBEST) [1,11], and criterion-based benchmarking (CBB) [12-14].

The calculated oRTU rates in this group of nine middle-income countries based on their disease distribution (52\%) did not differ from those found in developed countries; 48.3\% for Australia, [11] 41.5\% for Ontario [14] and 51\% (47-53.2\%) for Europe [15]. However, the actual RTU rates were consistently lower than oRTU rates.

The ESTRO-HERO group [15] calculated a 51\% (unweighted average) oRTU in 41 European countries following the EBEST method. The actual utilization rates were variable among these countries between $55.3 \%$ (Montenegro) to $31.8 \%$ (Ireland). In the ESTRO-HERO study, Slovenia was reported to have a $32.3 \%$, which is consistent with the $31 \%$ found in the present study. A large discrepancy was observed between the actual utilization and the optimal utilization of radiotherapy in European countries, with less than $17 \%$ of countries treating at least $80 \%$ of the optimal indications for radiotherapy and about $46 \%$ of the European countries not even reaching $70 \%$ of the patients optimally indicated. This ESTRO-HERO study illustrates that even in developed countries there is a gap between desirable and actual provision. The most critical impact on the RTU by country is due to changes in the relative frequency of tumours rather than disease stage at diagnosis. The effect of stage distribution is in the order of only $2 \%$ [15].

Zubizarreta et al. [16] calculated oRTU rates (EBEST method) as 54.3\% for Africa, 53.3\% for Latin America, 50.1\% for Europe/Central Asia and $49.5 \%$ for the Asia-Pacific region. These regional calculations compare with data previously published for developed countries and are in general agreement with the results of the present study.

An essential purpose of the RTU rate calculation is establishing the gap between the desirable (oRTU) and the actual (aRTU) rates at the country level. This deficit can be expressed as the difference between rate values or, more meaningfully, as the percent of the unmet need for radiotherapy, namely, the percentage of patients who despite having an indication for radiotherapy, do not have access to it. In the present study, the median unmet need for the nine countries was $47 \%$ (18\% Tunisia, $82.3 \%$ Ghana). The unmet need was particularly significant $(>80 \%)$ in two countries with limited resources and a large population. In the two states re-classified as "high income" countries (Uruguay and Slovenia), the unmet need was $29 \%$ and $35.4 \%$ respectively. The two countries that revealed a most pressing situation were Ghana, with an aRTU of $9 \%$ and the Philippines with $10.3 \%$.

In some countries, the aRTU for some specific diseases was surprisingly low compared with RTU rates reported from developed countries. For example, in Costa Rica, the aRTU for lung cancer was only $14.3 \%$ while the revised oRTU for lung cancer in Australia indicates 77\% [11], 59\% in British Columbia, Canada [17] and 77\% globally [22]. This low aRTU in Costa Rica may reflect an underreferral of lung cancer patients for RT.

In Romania, the aRTU for prostate cancer was found to be $9 \%$ while it has been reported as $25 \%$ (initial) in the Netherlands [18], 58\% in Australia [11] and 32\% (initial), 61\% (at 5-years) in British Columbia $[18,19]$ and 58\% globally [22] in the Netherlands [19]. The hypothesis is that in Romania most patients with localized prostate cancer are managed with surgery and hormone therapy.

Sarcomas were among the ten most commonly irradiated cancers in Costa Rica, Ghana, Serbia, and Tunisia. In a Swedish study 
Table 4

Number of anatomic sites irradiated per country in a series of 300 consecutive patients prospectively registered.

\begin{tabular}{|c|c|c|c|c|c|c|c|c|}
\hline Country & Central Nervous System & Head and Neck & Thorax & Abdomen & Pelvis & Breast cancer & Others (incl. limbs) & Total $\mathrm{n}$ of sites \\
\hline Costa Rica & 31 & 22 & 10 & 24 & 99 & 89 & 38 & 313 \\
\hline Ghana & 22 & 27 & 5 & 16 & 117 & 93 & 38 & 318 \\
\hline Malaysia & 33 & 66 & 13 & 10 & 76 & 71 & 47 & 316 \\
\hline Philippines & 41 & 61 & 31 & 1 & 84 & 71 & 19 & 308 \\
\hline Romania & 33 & 29 & 31 & 1 & 93 & 86 & 30 & 303 \\
\hline Serbia & 46 & 32 & 14 & 3 & 80 & 52 & 78 & 305 \\
\hline Slovenia & 48 & 38 & 61 & 23 & 58 & 55 & 39 & 322 \\
\hline Tunisia & 37 & 42 & 27 & 4 & 35 & 108 & 52 & 305 \\
\hline Uruguay & 10 & 9 & 12 & 1 & 49 & 58 & 17 & 156 \\
\hline Overall & 301 (11.4\%) & 326 (12.3\%) & 173 (6.5\%) & $83(3.1 \%)$ & $691(26.1 \%)$ & $683(25.8 \%)$ & 358 (13.5\%) & 2646 \\
\hline
\end{tabular}

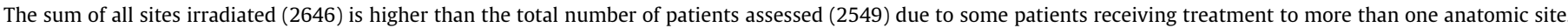

[21], In a Swedish study [20], the observed RTU rate was 55\% for sarcomas of bone and cartilage and $100 \%$ for soft-tissue sarcomas.

The ratio curative versus palliative-intention treatments was 0.6 meaning that $2 / 3$ of patients were managed with curative intent. This finding contradicts the assumption that in developing countries the majority of radiotherapy patients are treated for palliation. However, one must consider that this is a selected group of countries some of which have high-income country features. This finding cannot be extrapolated to low-income countries.

A correlation was found between the aRTU rates and the number of teletherapy machines per 1000 cancer cases/year in each country (Fig. 1). This association confirms that, although other access factors may be at play, availability of RT machines in a country is an important factor in RT utilization. However, availability of RT machines in itself by no means reflects access to modern and more sophisticated techniques. Some of these countries have an acceptable number of teletherapy machines related to their population but are struggling to introduce conformal and image-guided techniques.

Regarding a high "centre's delay" in Ghana, in African countries, the definition of delay used here is often confounded by patients who abscond radiotherapy, only to come back for treatment later and not delay due to the centre's operations themselves.

Re-treatment (or re-irradiation) describes a situation where a patient who has previously received radiotherapy, is prescribed and given a second course. This can be either to the same or similar original volume (true re-irradiation) or a different anatomical region due to metastatic spread of the same cancer diagnosis. The re-treatment rate in Australia has been determined to be as high as $25 \%$ [22]. In the present study, the re-treatment rate was calculated by subtraction of the reported new patients in 2012 from the total number of patients irradiated in each country in the same year. The median retreatment rate was $11 \%$. A possible explanation

\section{ACTUAL RTU RATE (\%)}

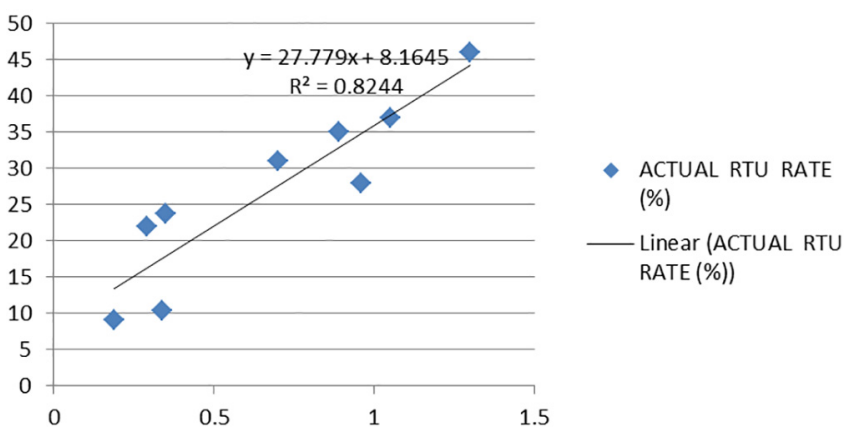

Fig. 1. Correlation between actual radiotherapy utilization rate (aRTU) and the number of megavoltage machines per 1000 cancer patients/year in 9 middleincome countries. may be a reluctance by radiation oncologists to prescribe a second course of radiotherapy to the same tissue volume in the face of a local recurrence, for concerns of excessive toxicity.

Atun et al. [23] have recently highlighted the obstacles facing radiotherapy availability worldwide and showed substantial health and economic benefits to investing in radiotherapy services. Steps to address this need include careful planning of radiotherapy services through international multisectoral partnerships and resource mobilization $[2,3]$. Not only will such planning ensure that all patients who could benefit from radiotherapy receive it, but will also potentially improve treatment results by reducing waiting times, which are known to have a detrimental effect on outcome in several cancer sites [24,25].

The case of Ontario, Canada [26], illustrates that radiotherapy utilization can be improved with a combination of a comprehensive capital investment strategy coupled with increased investment in human resource planning. The increased utilization rate outpaced the increasing cancer incidence and demonstrated the success of these strategies, providing better access to care in that province.

Population-based cancer registries have provided decisive contributions to cancer epidemiology and cancer control. In fact, cancer control planning without reliable data from cancer registries is prone to misplaced emphasis and wasted investment. All nine countries participating in this study have national cancer registries. The methods of estimation are country-specific, and the quality of the estimation depends upon the quality and the amount of the information available for each country. In theory, there are as many methods as countries, and because of the variety and the complexity of these methods, data from the Globocan-2012 database have been used.

A low aRTU rate and a high percent unmet need reflect problems with access to radiotherapy services. This is most likely due to a limited number of RT centres and/or megavoltage units (availability) relative to a large population. Other factors such as affordability, availability of diagnostic imaging and appropriate surgery, country geography, lack of awareness of patients and doctors, cultural beliefs and resorting to traditional forms of healing also play a role, but these factors were not the focus of this study.

Radiotherapy quality and access should be not only quantified but also monitored over time using appropriate radiation oncology quality indicators. National health authorities should conduct the long-range planning of cancer services including radiotherapy following international recommendations and the rich experience of countries that have already followed this path.

Limitations of this study include the selection of nine countries following pre-determined criteria. The GNI per capita was variable between 1513 US\$ (Ghana) to 21,650 US\$ (Slovenia). It has been previously shown that the level of economic development is correlated with the number of megavoltage machines (24). 
Finally, although this study did not include low-income countries, we can expect that in these countries, the aRTU rates will be even lower and the unmet need higher than those found here. Similar studies should be conducted in low-income countries identifying the factors that preclude access to radiotherapy services on a national level.

To conclude: actual RTU rates are lower than optimal RTU rates, and the level of unmet need for radiotherapy access is very significant in countries with limited resources and a large population.

\section{Conflict of interest statement}

The authors do not have any conflicts of interest to declare.

\section{Funding source}

The International Atomic Energy Agency, Vienna, Austria funded all meetings of national country coordinators, data collection and processing for this project.

\section{Appendix A. Supplementary data}

Supplementary data associated with this article can be found, in the online version, at https://doi.org/10.1016/j.radonc.2018.05. 014.

\section{References}

[1] Delaney G, Jacob S, Featherstone C, Barton M. The role of radiotherapy in cancer treatment: estimating optimal utilization from a review of evidencebased clinical guidelines. Cancer 2005;104(6):1129-37.

[2] International Atomic Energy Agency. Planning national radiotherapy services: a practical tool. Human Health Series 14. IAEA, Vienna; 2010.

[3] Rosenblatt E. Planning national radiotherapy services. Front Oncol 2014;4:315-9.

[4] Intersociety-Council for Radiation Oncology, Radiation Oncology in integrated cancer management. Report to the Director of the National Cancer Institute; 1991. Washington, DC.

[5] Frodin JE, Jonsson E, Moller T, Werkö L. Radiotherapy in Sweden: a study of present use in relation to the literature and an estimate of future trends. Acta Oncol 1996;5(8):967-79.

[6] Cleton FJ, Coebergh JW, and editors for the Steering Committee on Future Health Scenarios, Cancer in the Netherlands. K. Academic, Editor. Dordrecht, The Netherlands; 1991.

[7] The World Bank. World Bank Country and Lending Groups. 2012; Available from: https://datahelpdesk.worldbank.org/knowledgebase/articles/906519.
[8] Ferlay J, Soerjomataram I, Ervik M, Dikshit R, Eser S, Mathers C, et al. GLOBOCAN 2012 v1.0, Cancer Incidence and Mortality Worldwide: IARC CancerBase No. 11 [Internet]. Lyon, France: International Agency for Research on Cancer; 2013. Available from: http://globocan.iarc.fr, accessed on day/month/year.

[9] Rosenblatt E, Barton M, Mackillop W, et al. Optimal radiotherapy utilization rate in developing countries: an IAEA study. Radiother Oncol 2015;116 (1):35-7.

[10] Camacho R, Neves D, Piñeros M, et al. Prescription of cancer treatment modalities in developing countries: results from a multi-centre observational study. J Cancer Therapy 2014;5:989-99.

[11] Barton MB, Jacob S, Shafiq J, et al. Estimating the demand for radiotherapy from the evidence: a review of changes from 2003 to 2012. Radiother Oncol 2014;112(1):140-4.

[12] Kerba M, Miao Q, Zhang-Salomons J, Mackillop W. Defining the need for breast cancer radiotherapy in the General population: a criterion-based benchmarking approach. Clin Oncol (R Coll Radiol) 2007;19(7):481-9.

[13] Kerba M, Miao Q, Zhang-Salomons J, Mackillop W. Defining the need for prostate cancer radiotherapy in the general population: a criterion-based benchmarking approach. Clin Oncol (R Coll Radiol) 2010;22(10):801-9.

[14] Mackillop WJ, Kong W, Brundage M, et al. A comparison of evidence-based estimates and empirical benchmarks of the appropriate rate of use of radiation therapy in Ontario. Int J Radiat Oncol Biol Phys 2015;91(5):1099-107.

[15] Borras JM, Lievens Y, Dunscombe P, et al. The optimal utilization proportion of external Beam radiotherapy in European countries: an ESTRO-HERO analysis. Radiother Oncol 2015;116(1):38-44.

[16] Zubizarreta EH, Fidarova E, Healy B, Rosenblatt E. Need for radiotherapy in low and middle-income countries - The silent crisis continues. Clin Oncol (R Coll Radiol) 2015;27(2):107-14.

[17] Tyldesley S, Boyd C, Schultze K, Walker H, Mackillop WJ. Estimating the need for radiotherapy for lung cancer: an evidence-based, epidemiologic approach. Int J Radiat Oncol Biol Phys 2001;49(4):973-85.

[18] Poortmans PM, Aarts MJ, Jobsen JJ, et al. A population-based study on the utilization rate of primary radiotherapy for prostate cancer in 4 regions in the Netherlands, 1997-2008. Radiother Oncol 2011;99(2):207-13.

[19] Tyldesley S, Delaney G, Foroudi F, Barbera L, Kerba M, Mackillop W. Estimating the need for radiotherapy for patients with prostate, breast, and lung cancers: verification of model estimates of need with radiotherapy utilization data from British Columbia. Int J Radiat Oncol Biol Phys 2011;79(5):1507-15.

[20] Foroudi F, Tyldesley S, Barbera L, Huang J, Mackillop WJ. Evidence-based estimate of appropriate radiotherapy utilization rate for prostate cancer. Int J Radiat Oncol Biol Phys 2003;55(1):51-63.

[21] Möller TR, Brorrson B, Ceberg J, et al. A prospective survey of radiotherapy practice 2001 in Sweden. Acta Oncol 2003;42(5-6):387-410.

[22] Barton MB, Allen S, Delaney GP, et al. Patterns of retreatment by radiotherapy. Clin Oncol (R Coll Radiol) 2014;26(10):611-8.

[23] Atun R, Jaffray D, Barton MB, et al. Expanding global access to radiotherapy. Lancet Oncol 2015;16(10):1153-86.

[24] Huang J, Barbera L, Brouwers M, Browman G, Mackillop WJ. Does delay in starting treatment affect the outcomes of radiotherapy? A systematic review. J Clin Oncol 2003;21(3):555-63.

[25] Mackillop WJ, Bates JH, O'Sullivan B, Withers HR. The effect of delay in treatment on local control by radiotherapy. Int J Radiat Oncol Biol Phys 1996;34(1):243-50.

[26] Ang M, Gutierrez E, Foster N, Favell L, Warde PR. Improving radiotherapy utilization rates in Ontario. J Clin Oncol 2014;32(30_suppl). 48-48. 